\title{
REFORMA LEGISLATIVA DE LA TELEVISIÓN ANTE EL FUTURO DIGITAL UN PASO ADELANTE, UNO ATRÁS*
}

\section{Lucas Sierra}

\begin{abstract}
Este trabajo analiza críticamente la propuesta de reforma a la legislación televisiva que el Gobierno ha enviado al Congreso con miras a la futura tecnología digital. La reforma está conformada por dos proyectos de ley: uno se refiere a la Ley 18.838, general de televisión, y el otro a la Ley 19.132, sobre Televisión Nacional de Chile. Ambos proyectos son analizados aquí. El primero, se sostiene, propone un avance interesante: la incorporación de la categoría de servicios
\end{abstract}

LuCAS Sierra I. Abogado, Universidad de Chile; LL.M. Universidad de Yale; Ph.D., Universidad de Cambridge. Profesor de Derecho de las Telecomunicaciones, Universidad de Chile. Investigador del CEP.

* Agradezco las interesantes conversaciones que tuve con Eduardo Costoya y Marcelo Pandolfo mientras escribía este trabajo, la ayuda de Pablo Fuenzalida y los útiles comentarios de Harald Beyer, Arturo Fontaine T. y Lucas Mac-Clure. Una versión preliminar de este trabajo se publicó en marzo de 2009 como Documento de Trabajo 376 del CEP, bajo el mismo título. Esa versión fue presentada en un seminario público realizado en el CEP el 4 de mayo de 2009. En esa oportunidad recibí algunos comentarios del ministro René Cortázar, que agradezco muy especialmente. Como es obvio, ninguna de estas personas tiene responsabilidad alguna por los errores u omisiones que puedan haber quedado.

[Estando este número de Estudios Públicos en prensa, el Gobierno envió a la Cámara de Diputados, bajo el N 762-357, una indicación para modificar algunos puntos del "Proyecto de Ley que Permite la Introducción de la Televisión Digital Terrestre", a que se refiere este artículo. Sin embargo, esa indicación no altera el diagnóstico ni las conclusiones de este artículo. (N. del Autor.)] 
“intermedios" de telecomunicaciones a la futura radiodifusión televisiva digital. Éste es un paso en el sentido de la convergencia que la tecnología digital impulsa entre los distintos servicios de telecomunicaciones. Este avance, sin embargo, se ve empeñado por otras propuestas del proyecto, como, por ejemplo, el establecimiento de "campañas de utilidad o interés público" obligatorias para los canales, lo que representa una intervención estatal injustificada. El segundo proyecto, sobre Televisión Nacional de Chile, también es criticado. La razón fundamental es que extiende y difumina el giro de esta empresa del Estado, echando una sombra de duda sobre el criterio de subsidiariedad estatal que inspira nuestra regulación económica, al tiempo que se propone quebrar el pie de igualdad que existe entre la televisión estatal y la privada. En síntesis, se concluye, esta reforma legislativa da un paso adelante, pero también uno atrás.

Palabras clave: Televisión, radiodifusión, televisión pública, digitalización, telecomunicaciones, regulación, espectro radioeléctrico.

\section{Introducción}

L

as páginas que siguen analizan la reforma legislativa que el Gobierno ha iniciado en vista de la futura llegada de la televisión digital a Chile. En noviembre del año pasado, el Gobierno envió al Congreso dos proyectos de ley: uno que modifica la Ley de Televisión, Ley 18.838, y otro que modifica la Ley de Televisión Nacional de Chile (TVN), Ley 19.132르. Es, en otras palabras, una reforma a la legislación de la televisión "abierta” o, más técnicamente, radiodifusión televisiva².

Esta reforma legislativa se ha iniciado con independencia del estándar técnico de televisión digital que se vaya a adoptar en el futuro,

${ }^{1}$ El primer proyecto corresponde a "Mensaje de S. E. la Presidenta de la República, con el que Inicia un Proyecto de Ley que Permite la Introducción de la Televisión Digital Terrestre”. Ingresó a la Cámara de Diputados con el Boletín 6190-19, el 06/11/ 2008. Ver http://www.camara.cl/pley/pley_detalle.aspx?prmID=6579\&prmBL=6190-19. El segundo proyecto corresponde a "Mensaje de S. E. la Presidenta de la República con el que Inicia un Proyecto de Ley que Modifica la Ley No 19.132 de Televisión Nacional de Chile”. Ingresó a la Cámara de Diputados con el Boletín 6191-19, el 06/11/2008. Ver http://www.camara.cl/pley/pley_detalle.aspx?prmID=6578\&prmBL=6191-19

${ }^{2}$ Cuando en este trabajo se habla de televisión, sin más, debe entenderse la televisión “abierta” o, como la define la Ley 16.168, General de Telecomunicaciones, la radiodifusión televisiva de libre recepción, esto es, la que es recibida "libre y directamente” por el público en general. 
cuestión que es competencia del Gobierno resolver mediante un acto administrativo. Hasta cierto punto, ambas cuestiones pueden tratarse con independencia.

Este trabajo examinará ambos proyectos de ley. En la primera parte (1) se analiza el que busca reformar la Ley 18.838, de radiodifusión televisiva. A la luz de este análisis, luego en (2) se estudia el proyecto que intenta reformar la Ley 19.132 sobre TVN. Por último, en (3), se avanzan algunas conclusiones. Éstas sostienen que esta reforma legislativa iniciada por el Gobierno contiene una cuestión interesante: la introducción de la categoría de servicios "intermedios” en la regulación televisiva. Sin embargo, también sostienen que la reforma contiene varias cuestiones negativas, las que, consideradas en conjunto, enturbian el interesante potencial que podría tener la introducción de la mencionada categoría de servicios "intermedios" en la TV abierta. Si se eliminaran estas cuestiones, la reforma podría aprovechar mejor el potencial que para nuestra radiodifusión televisiva promete la tecnología digital.

\section{LA REFORMA DE LA LEY 18.838, SOBRE LA TELEVISIÓN EN GENERAL}

Este proyecto sugiere varios cambios a esta ley. A juicio de este trabajo, los más relevantes son el que se refiere a las "campañas de utilidad o interés público” del Gobierno, el que aumenta los poderes regulatorios del Consejo Nacional de Televisión (CNTV) sobre cierta publicidad televisiva, así como los que se refieren a la división geográfica de las nuevas concesiones de radiodifusión televisiva, al ingreso a esta radiodifusión de nuevas concesiones de servicios "intermedios" de telecomunicaciones, al destino de las actuales concesiones de televisión que son indefinidas en el tiempo, y al plazo que se establece para migrar hacia la televisión digital. A continuación, cada uno de estos cambios se analiza en ese orden.

\subsection{Campañas de "utilidad o interés público"}

Es negativo que esta oportunidad no se haya aprovechado para revisar la necesidad de tener un órgano regulador específico para la televisión: el Consejo Nacional de TV (CNTV). El proyecto de ley no sólo no deroga este órgano, sino que, en un sentido importante, lo 
refuerza: ahora, en conjunto con el Gobierno de turno, podrá obligar a los canales a emitir ciertas “campañas” decididas por el Gobierno. Es la resurrección de las antiguas "cadenas” televisivas. En lugar de que esta reforma refuerce la autonomía editorial en la televisión, lo que hace es aumentar el poder relativo del Estado frente a ella, amenazándola, por tanto.

Esta posibilidad de forzar la transmisión de ciertos contenidos es uno de los aspectos negativos de la reforma. El proyecto introduce las llamadas "campañas de utilidad o interés público", mediante las cuales el Gobierno puede pedirle al CNTV que imponga a los canales la emisión de los contenidos que el Gobierno determine, conforme al siguiente criterio general: "Se entenderá por campaña de interés público a aquellas transmisiones diseñadas por las autoridades competentes, que se han de emitir con el objeto de proteger a la población y difundir el respeto y promoción de los derechos de las personas”.

Estas “campañas de utilidad o interés público" traen de vuelta la lógica de las antiguas "cadenas” de televisión, práctica intervencionista usada en el pasado y desterrada desde que se recuperó la democracia en 1990. ¿Por qué resucitarla hoy, aunque sea en la forma más edulcorada que el proyecto propone? Desde 1990 el Gobierno ha podido dar a conocer sus campañas en todo Chile. Paga por ellas y los canales, incluyendo TVN, por supuesto, se han encargado de transmitirlas en todo el país. Algunas han generado controversias, como las orientadas a prevenir el sida. Un par de estaciones, al amparo de su autonomía editorial, se negaron a transmitir las campañas del Gobierno, que incluían el uso de condones como una de las alternativas de prevención. En reemplazo, idearon y transmitieron sus propias campañas, enfatizando otras alternativas preventivas. Pero siempre existió la posibilidad de recibir por televisión el mensaje del Gobierno en todo el país.

Los medios de comunicación deben pensarse como un sistema, lo mismo los medios televisivos de comunicación. A través de este sistema, las campañas que diseñe y financie el Gobierno siempre encontrarán una forma de transmitirse, sobre todo si existe un canal estatal que, como TVN, tiene cobertura nacional.

El mecanismo propuesto por el proyecto es así: “...el Ministerio Secretaría General de Gobierno determinará cuáles serán las campañas de utilidad o interés públicos, enviando la estructura, diseño y contenidos fundamentales de la o las campañas al Consejo [Nacional de TV], 
el que deberá aprobarlas con el voto conforme de al menos seis de sus miembros en ejercicio. Producida su aprobación, el Consejo remitirá a los concesionarios la resolución respectiva con todos sus antecedentes, junto a las instrucciones adicionales que fueren necesarias para la transmisión de la campaña con vistas en el cumplimiento de los objetivos de la misma”. El proyecto deja a cada concesionaria la determinación de la "forma y contenido de los spots", pero, una vez que los hayan definido, deberán someterlos a la "aprobación previa del Consejo".

Llama la atención que esta norma se introduzca sin modificar lo dispuesto en el art. 13 de la Ley 18.838, que dispone: "El Consejo no podrá intervenir en la programación de los servicios de radiodifusión televisiva de libre recepción ni en la de los servicios limitados de televisión”. La imposición de estas “campañas” por parte del Gobierno y del CNTV es una evidente intervención en la programación televisiva, aunque se deje la definición precisa de la "forma y contenido de los spots” a las propias estaciones. Finalmente, todas las campañas deben ser aprobadas por la autoridad estatal.

Esta propuesta sugiere una intervención excesiva del Estado en la autonomía editorial de los medios de comunicación televisivos, exceso que resulta aún más evidente si se considera lo innecesaria que ella parece ser hoy en día. Además, ni la radiodifusión sonora, ni la prensa escrita, ni los medios electrónicos están sujetos a una intervención así. Por todo esto, la resurrección de las “cadenas" televisivas enfrenta la formidable muralla que para ellas significa la sentencia 226 que el Tribunal Constitucional dictó en 1995. Aquí el Tribunal Constitucional afirmó enfáticamente el valor de la autonomía editorial de los medios de comunicación:

... desde el momento en que se impone al Estado la obligación de equilibrar el flujo noticioso a fin de pretender una pluralidad ideológica o cultural, y para así hacerlo ha de imponer obligaciones a los medios de comunicación social, significa una intromisión indebida en las decisiones que pueda adoptar un medio de comunicación, interferencia que no sólo constituye una clara violación a la autonomía de ese medio... sino, además, una violación directa a la libertad de emitir opinión y de informar — que reconoce, asegura y protege la Carta Fundamental en su artículo 19, $\mathrm{N}^{\circ} 12$-, sin censura previa, en cualquier forma y por cualquier medio. Y es más; afecta dicha 
disposición requerida del proyecto al “contenido esencial” de esta libertad, puesto que significa imponer condiciones que impiden su libre ejercicio; y es que se afecta su esencia desde el mismo instante en que su ejercicio deja de ser libre ${ }^{3}$.

En consecuencia, esta propuesta del proyecto podría estar expuesta a un reproche por inconstitucionalidad.

\subsection{Regulación de la publicidad televisiva durante ciertos programas}

El proyecto de ley incluye otra propuesta sobre contenidos televisivos que también despierta dudas. Se refiere a cierta publicidad televisiva, ampliando y reforzando los poderes que el CNTV tiene sobre ella. Hoy en día, el CNTV tiene pocos poderes específicos sobre la publicidad: el principio general vigente es que las estaciones la deciden autónomamente, bajo las reglas, claro, que regulan el contenido televisivo en general (así, por ejemplo, está prohibido emitir publicidad pornográfica $)^{4}$.

Este principio general de autonomía publicitaria se aplica también a la publicidad que se emite durante programas que hayan sido financiados con los recursos fiscales que adjudica el CNTV mediante sus concursos públicos. Es decir, si una estación hoy emite una película cuya realización se benefició con estos fondos públicos, es libre para decidir la publicidad que intercala, tal como lo es si lo que emite es una película comprada por la estación a un distribuidor internacional.

Hasta hoy, el CNTV tampoco ha regulado la publicidad en atención al carácter del asunto publicitado, con la sola excepción de la publicidad de tabaco y bebidas alcohólicas, que sólo puede emitirse en horario adulto, es decir, entre las 22:00 y las 06:00 horas, y la publicidad de drogas ilícitas, que no puede emitirse en horario alguno.

\footnotetext{
${ }^{3}$ Considerando $31^{\circ}$ de la sentencia Rol 226, Tribunal Constitucional (1995).

${ }^{4}$ El proyecto define "publicidad" en los siguientes términos: "Para los efectos de este artículo, se entenderá por publicidad todo mensaje transmitido a cambio de una remuneración o contraprestación, por cuenta de una persona natural o de una persona jurídica de derecho privado, relativa a una actividad comercial, industrial, artesanal o profesional, realizada con el objeto de promocionar el suministro de bienes de toda clase o la prestación de servicios, con carácter oneroso. No constituyen publicidad para estos efectos, los anuncios realizados por el concesionario en relación con sus propios programas y los productos accesorios directamente derivados de dichos programas”.
} 
El proyecto del Gobierno busca cambiar esto, a fin de dar poder al CNTV para que regule la publicidad que se intercale en emisiones beneficiadas con fondos fiscales. Dice el proyecto:

En el caso de la letra b) del artículo precedente [programación que recibió subsidio fiscal], el Consejo podrá fijar los resguardos para que cuando se inserte publicidad televisiva durante las producciones financiadas con estos recursos, no se exceda una proporción que el mismo Consejo determine de anuncios de publicidad televisiva. Tratándose de películas realizadas para la televisión, con exclusión de las series, los seriales y los documentales, otras obras cinematográficas y programas informativos, podrán ser interrumpidos por publicidad la cantidad de veces que el Consejo determine.

Además de poder regular el traslape entre programas subsidiados y publicidad, el proyecto también da al CNTV el poder de regular la publicidad durante esos programas en atención a los productos publicitados. Dice el proyecto: “Asimismo, el Consejo podrá limitar el horario y duración de los anuncios publicitarios relativos a sustancias destinadas al consumo humano y sujetas al control de la autoridad sanitaria”. Además del tabaco y del alcohol, entonces, el proyecto busca que el CNTV regule durante los programas subsidiados la publicidad de un muy amplio espectro de productos, desde la leche hasta las bebidas gaseosas, pasando por duraznos en conserva, helados, chocolates, yogur y remedios para el resfrío.

Aun cuando se trata de un poder que sólo se puede ejercer respecto de la publicidad durante los programas subsidiados, la expresión que usa el proyecto: "sustancias destinadas al consumo humano y sujetas al control de la autoridad sanitaria” es excesivamente amplia y ambigua. Por lo mismo, pone demasiada discrecionalidad en las manos del regulador. ¿Cuál es la razón que justifica esta nueva intervención estatal? Como con las cadenas televisivas, con la publicidad el proyecto de ley constituye un retroceso poco comprensible. Parece estar aflorando nuevamente algo de esa animadversión regulatoria contra la publicidad televisiva que tuvo la primera ley de televisión en 1970 (Ley 17.377). Quienes promuevan esta regulación específica de la publicidad televisiva deberán justificarla suficientemente, pues hasta ahora no parece justificada. 
Además, esta propuesta de regulación publicitaria parece discriminatoria frente a otros medios de comunicación que, aun cuando difundan contenidos que han recibido subsidios de los otros fondos que tiene el Estado para el contenido simbólico, pueden intercalar publicidad sin las restricciones que se quieren imponer a la radiodifusión televisiva. De aprobarse esta propuesta, el CNTV podrá regular especialmente la propaganda televisiva del yogur, pero esta misma sustancia podrá ser anunciada sin regulación especial alguna en la radio y en un libro, aun cuando el programa radial o publicación de que se trate haya recibido subsidios fiscales. ¿Qué justifica este trato diferenciado, que agrava el trato diferenciado que ya recibe la televisión respecto del tabaco y alcohol?

Y, para volver a la primera restricción que el proyecto propone, ¿qué justifica restringir la publicidad en la emisión de contenidos producidos con recursos fiscales? Tampoco se ve aquí con claridad una respuesta satisfactoria. Paradójicamente, esta restricción podría tener consecuencias opuestas a los objetivos que se persiguen con el subsidio fiscal a la programación televisiva, que es la producción y difusión de contenidos nacionales de calidad. Si se regula de forma especial la publicidad durante la emisión de estos contenidos, se arriesga disminuir los incentivos que pueden tener las estaciones para transmitir dichos contenidos. Quizás esto pueda afectar proporcionalmente más a las estaciones chicas que a las grandes, contradiciéndose así otro objetivo que se busca con este proyecto: la coexistencia de múltiples estaciones distintas. Para disminuir este riesgo, habría que empezar a distinguir entre las distintas estaciones, porque una regulación así puede afectar de manera distinta a las estaciones grandes y chicas. O distinguir entre subsidios dados para la producción de un programa y los dados para su transmisión. Y un problema más. ¿Qué pasa si un contenido televisivo recibió un subsidio que alcanzó sólo a un $40 \%$ de su costo total? ¿El CNTV deberá regular la publicidad durante su emisión en ese mismo porcentaje? Hacer todo esto parece muy complicado y exigiría una ingeniería social excesiva por parte del CNTV. ¿Vale la pena? Quizás sea mejor en esta materia la ley como está, sin una regulación especial de la publicidad durante la emisión de contenidos subsidiados. $\mathrm{O}$, al menos, no modificarla antes de entender mejor cómo operará en la 
práctica la televisión digital. O, por último, si se insiste con esta propuesta, establecer criterios más precisos en la propia ley, a fin de reducir la discrecionalidad del CNTV 5 .

\subsection{División geográfica de la radiodifusión televisiva}

Por su lado, esta propuesta distingue entre distintas concesiones de radiodifusión televisiva: nacionales, regionales, locales y comunitarias. Hasta ahora, la ley no hace distinción entre las concesiones de radiodifusión televisiva. Todas son, simplemente, concesiones de radiodifusión televisiva, que se ejercen sobre un área geográfica determinada o zona de servicio. El territorio está dividido en varias áreas de cobertura, y para cada una de ellas se han establecido concesiones de radiodifusión televisiva. Así, una diferencia entre una concesionaria grande, como TVN, y una chica, como UCV-TV, es que la primera es titular de concesiones en más zonas de servicio que la segunda (TVN es titular de 207 concesiones, UCV-TV de 8). Por otro lado, y a diferencia de la radiodifusión sonora (la radio), hoy no existe legalmente la radiodifusión televisiva "comunitaria”6.

El proyecto propone ahora distinguir entre los siguientes cuatro tipos de concesiones de radiodifusión televisiva de libre recepción:

- $\quad$ Nacionales, que contemplan una cobertura en más del 50\% de las regiones del país, cualquiera sea el nivel de cobertura que alcancen en cada región;

${ }^{5}$ Es conveniente tener presente aquí la práctica y evolución de la Ley 18.985 de 1990, Ley de Donaciones Culturales, o “Ley Valdés”. Su texto original dispuso que si una exposición o espectáculo recibía donaciones sujetas a esa ley, "la asistencia a los mismos deberá ser gratuita y estar abierta al público en general”. Las consecuencias de esta disposición fueron problemáticas, lo que llevó a su modificación en el año 2001. Se hizo más flexible, permitiéndose, bajo ciertas condiciones, las donaciones a exposiciones y espectáculos pagados. Esta evolución enseña que no es simple la relación subsidio fiscal/ gratuidad. Menos simple es respecto de la radiodifusión televisiva, en la que los costos de producir y de emitir muestran entre sí una diferencia mayor que en el caso de, por ejemplo, una exposición fotográfica.

${ }^{6}$ Aunque en la práctica sí existe. En Santiago, por ejemplo, en la población La Victoria, se opera una emisora de TV, definida como "comunitaria" y con un radio de alcance cercano a los 10 kilómetros. Ver http://canal3lavictoria.cl/index.php. Por su parte, las radios comunitarias fueron consagradas legislativamente en 1992, cuando una modificación de la Ley 18.838, General de Telecomunicaciones, incorporó los servicios de radiodifusión de "mínima cobertura". 
- $\quad$ Regionales, que contemplan una cobertura hasta del 50\% de las comunas de una región, y que tienen un alcance efectivo igual o superior a un 25\% de su población, pero en no más del 50\% de las regiones del país;

- Locales, que contemplan una cobertura en sólo una región, pero comprendiendo dentro de ella un alcance efectivo inferior al $25 \%$ de su población o con una cobertura igual o inferior al 50\% de las comunas de dicha región, y

- $\quad$ Comunitarias, que contemplan las mismas condiciones de cobertura de las concesiones locales, ya mencionadas, y, además, sus titulares cumplen ciertos requisitos señalados en el mismo proyecto de ley.

Esta distinción tiene consecuencia en el espectro radioeléctrico destinado a la radiodifusión televisiva: el $40 \%$ de él debe reservarse para concesiones regionales, locales, comunitarias y aquellas que, siendo nacionales, el CNTV califique como “culturales”. Es decir, se deja para las "nacionales" no "culturales" el $60 \%$ de todo este espectro. Actualmente se ha reservado para la televisión digital el espectro que va, en la banda UHF, desde la frecuencia 21 hasta la 36 y desde la 38 hasta la 59. Es decir, 38 frecuencias. El 60\% equivale a 23 frecuencias, el $40 \%$ a 15. Hay 23 frecuencias para las concesiones nacionales no "culturales”. Si este proyecto entrara en vigencia hoy, habría seis titulares de concesiones nacionales no “culturales”: TVN, UC-TV, Mega, La RedTV, Chilevisión (por sí sola, sin necesidad de las que es titular la Universidad de Chile y que hoy Chilevisión usufructa), y la propia Universidad de Chile. Es decir, habría espacio espectral para 15 titulares de concesiones nacionales no "culturales” más. También habría algunos titulares de concesiones "regionales": UCV-TV, Canal-2, y R.D.T. S.A. en el sur de Chile. Y habría, además, algunas "locales” y "comunitarias".

El hecho de que se haya reservado la banda de frecuencias UHF para la televisión digital, haciendo emigrar la radiodifusión televisiva desde la banda VHF que mayormente usa hoy, ha sido objeto de alguna crítica. La banda UHF tiene menor capacidad de propagación que la banda VHF. Esto significa que para alcanzar la misma cobertura, en la banda UHF se requiere un transmisor más potente que en la banda VHF. Además, las señales en la banda VHF tienen más facilidad de 
sortear los obstáculos que encuentran a su paso. En síntesis, en la banda VHF la radiodifusión televisiva es más barata que en la banda UHF. Si uno de los objetivos de este proyecto es potenciar la radiodifusión televisiva local y comunitaria, como se dice, el uso de la banda VHF aparece como más funcional a este objetivo que el uso de la $\mathrm{UHF}^{7}$. Hay un buen punto en esta crítica. Frente a ella, el Gobierno podría argumentar que en la banda VHF hay menos frecuencias disponibles (sólo 12), y que en algunas zonas (como Santiago, por ejemplo) esa banda está bastante saturada. Un buen punto también. Ambos deberían considerarse durante el debate legislativo.

Asimismo se han presentado dudas sobre la posibilidad de que las concesiones "nacionales" impliquen el establecimiento de "redes de frecuencia única" (SNF en sus siglas en inglés). Esto significa que un mismo titular de concesión tenga, en todo el territorio nacional, la misma frecuencia para su señal. Un ejemplo: bajo el esquema SNF TVN podría usar la frecuencia 7 en todo el territorio nacional y no como hoy que, bajo el sistema de "redes de frecuencia múltiple" (MNF) existente, TVN usa la frecuencia 7 en Santiago, pero la 12 en Valparaíso y la 4 en Puerto Montt. El proyecto no propone explícitamente ni SNF ni MNF, pero la idea de concesión "nacional” se ha visto como un posible incentivo para la SNF. ¿Cuál sería aquí el problema? SNF permite una mayor eficiencia en el uso del espectro radioeléctrico, pero también impone algunas rigideces: la frecuencia de todos los transmisores debe estar totalmente sincronizada y el contenido emitido por todos ellos debe ser exactamente el mismo, al mismo tiempo. Esto imposibilitaría una práctica que desarrollan hoy las concesionarias que, como TVN, operan una red nacional: emitir cierta programación local intercalándola en la programación nacional (por ejemplo, en el noticiario central). Si uno de los objetivos de este proyecto es incentivar la producción y emisión de contenidos televisivos locales, la SNF podría ser aquí contraproducente. Además, esta opción podría encarecer la distribución del contenido a toda la red. Hoy ésta se hace vía satélite. Pero la SNF parece dificultar una distribución por esta vía, creando la necesidad de otras vías que, como la fibra óptica, son más caras. La topología del territorio chileno, se dice, favorece la MNF, pues tiene accidentes naturales que aíslan las emisiones distintas en zonas de (2008).

${ }^{7}$ Ver, por ejemplo, la presentación del Colegio de Ingenieros de Chile A. G. 
servicio distintas, pero que usan la misma frecuencia. A la luz de todo esto, el debate legislativo también deberá considerar con cuidado este punto $^{8}$.

Finalmente, un punto sobre las nuevas concesiones de radiodifusión locales y comunitarias que se proponen. Junto con asegurarles a éstas y a las regionales y aquellas nacionales que el CNTV califique como “culturales” un mínimo de espectro radioeléctrico, el proyecto dispone un subsidio fiscal preferente para las concesionarias locales y comunitarias. Hasta ahora, la ley autoriza al CNTV para recibir todos los años recursos fiscales destinados a "financiar o subsidiar la producción, transmisión y difusión de programas televisivos en aquellas zonas fronterizas, extremas o apartadas del territorio nacional en que, por su lejanía o escasa población, no exista interés comercial que incentive a concesionarias de servicio de radiodifusión televisiva de libre recepción a prestar estos servicios”. El proyecto amplía las hipótesis que dan lugar al subsidio en los siguientes términos: "El Consejo podrá recibir aportes especiales del Estado para financiar o subsidiar la producción, transmisión y difusión de programas televisivos en aquellas zonas del territorio nacional en que, por su lejanía o escasa población, alto costo de inversión, baja rentabilidad económica u otra causa de entidad semejante, no exista interés comercial que incentive a concesionarias de servicio de radiodifusión televisiva de libre recepción a prestar estos servicios”.

La propuesta es menos precisa que la legislación vigente, lo que puede dar lugar a arbitrariedad en la asignación de estos recursos. Ahora se habla de "alto costo de inversión, baja rentabilidad económica u otra causa semejante”. La ambigüedad de esta última expresión es patente. Además, se agrega el subsidio preferente para la radiodifusión televisiva local y comunitaria: "Dichos aportes se emplearán preferentemente para financiar o subsidiar la producción y transmisión de los concesionarios de servicio de radiodifusión televisiva de libre recepción de carácter comunitario y local”. En principio, esto no parece incorrecto, pero sí puede dar lugar a las dificultades prácticas que se pueden derivar del interés de los parlamentarios representantes de las localidades en que se encuentren dichos radiodifusores, por aumentar excesivamente el ítem correspondiente en las respectivas leyes de presupuesto. Ésta es una posibilidad que conviene tener presente.

\footnotetext{
${ }^{8}$ Sobre la disyuntiva entre SNF y MNF, ver también la presentación del Colegio de Ingenieros de Chile A. G. (2008).
} 
Dicho todo esto, revisemos ahora la división en dos que el proyecto propone para las concesiones de la radiodifusión televisiva digital que es, quizás, la propuesta más interesante de esta reforma.

\subsection{Concesión de servicios "intermedios" para la televisión}

Hasta hoy, una concesión de radiodifusión televisiva de libre recepción es una autorización para emitir contenidos audiovisuales, más la entrega del espectro radioeléctrico necesario para hacerlo. Es una autorización para emitir, más el recurso que requiere la emisión. Aquí hay un cambio importante que el proyecto busca introducir: que la concesión de radiodifusión sea nada más que una autorización para emitir televisión, pero que no se extienda al espectro requerido. Para éste se requiere un título distinto, separado de la concesión de radiodifusión. Este otro título es una concesión de servicio "intermedio", que da acceso al espectro radioeléctrico. Hay que precisar, con todo, que el proyecto reserva esta distinción para las concesiones "nacionales” y "regionales", pero no para las "locales" ni para las "comunitarias". Éstas se mantienen con el esquema vigente: la concesión de radiodifusión televisiva digital terrestre, además de ser una autorización para emitir contenidos audiovisuales, es también una autorización para usar el espectro radioeléctrico que esa emisión requiere.

Si bien centrada en las concesiones nacionales y regionales, la propuesta de una concesión de radiodifusión y de otra, distinta, de servicios "intermedios", es la más interesante del proyecto y la que busca de modo más directo hacerse cargo del cambio digital. Si se materializa, una persona jurídica que quiera emitir televisión deberá pedirle al CNTV una concesión de radiodifusión televisiva de libre recepción y, si quiere, una de servicios “intermedios” para la emisión de la correspondiente señal, que entrega el Ministerio de Transportes y Telecomunicaciones ${ }^{9}$. O, tal vez, puede pedir sólo una concesión de

\footnotetext{
${ }^{9}$ Llama la atención que, a las puertas del futuro digital y de la abundancia relativa de espectro radioeléctrico que éste posibilita, la legislación mantenga la exigencia de que los titulares de concesiones de radiodifusión televisiva sean personas jurídicas y no, también, personas naturales. Hay que recordar que el texto original de la Ley 18.838, vigente entre 1989 y 1992, contemplaba la posibilidad de que las personas naturales fueran, también, titulares de estas concesiones. Si se quiere fomentar la diversidad y el pluralismo en televisión, habría que posibilitar una mayor diversidad de concesionarios posibles.
} 
radiodifusión televisiva, pero no una de servicios “intermedios”. Esto, pues pretende acordar con una concesionaria de servicios "intermedios” el transporte de su señal. De esta manera, la autorización para la radiodifusión televisiva se ha dividido en dos: en la autorización para emitir televisión, por un lado, y en el acceso al espectro radioeléctrico necesario para hacerlo, por el otro. Esta división permite el surgimiento de los siguientes agentes en el negocio televisivo:

1. Concesionarios de radiodifusión televisiva que, a la vez, son concesionarios de servicios "intermedios" para el transporte de su propia señal.

2. Concesionarios de radiodifusión televisiva que no son titulares de una concesión de servicios "intermedios", pero que contratan con titulares de estas últimas concesiones para el transporte de su señal.

3. Concesionarios de servicios "intermedios" que no son titulares de una concesión de radiodifusión televisiva, pero que contratan con estos titulares para transportarles su señal.

La incorporación de la categoría de servicios “intermedios” a la radiodifusión televisiva es, como se ha dicho, quizás lo más interesante del proyecto de ley. Sin embargo, esta innovación plantea la pregunta por la razón de conservar las concesiones de radiodifusión, pero ahora como meras autorizaciones para emitir contenidos audiovisuales, sin el espectro necesario para hacerlo. ¿Por qué regular tanto, mediante una autorización que se otorga por decreto supremo, como son las concesiones, la mera posibilidad de emitir contenidos audiovisuales? Quizás sería más sensato y económico tener sólo concesiones de servicios “intermedios" en el negocio televisivo, sin concesiones adicionales de radiodifusión que, a simple vista, parecen algo inútiles, al basarse en una distinción que no tiene mucho sentido: producir y disponer contenidos audiovisuales en general (que no necesita autorización estatal alguna), por una parte, y, por la otra, producir y disponer contenidos audiovisuales para que sean emitidos en televisión (que requiere de concesión). Planteada esta pregunta, que ojalá se responda durante el debate legislativo, veamos ahora la concesión de servicios "intermedios".

El proyecto sugiere que las concesiones de servicios "intermedios” que está introduciendo a la radiodifusión televisiva son las conce- 
siones de servicios "intermedios" de la ley de telecomunicaciones, es decir, tienen el objeto amplio de esas concesiones. Así define la Ley 18.168, General de Telecomunicaciones, a los servicios “intermedios":

\begin{abstract}
Servicios "intermedios" de telecomunicaciones, constituidos por los servicios prestados por terceros, a través de instalaciones y redes, destinados a satisfacer las necesidades de transmisión o conmutación de los concesionarios o permisionarios de telecomunicaciones en general, o a prestar servicio telefónico de larga distancia a la comunidad en general.
\end{abstract}

Como se ve, el objeto de las concesiones de servicios "intermedios” es muy amplio, pues incluye las necesidades de transmisión o conmutación que puedan llegar a tener los prestadores de servicios de telecomunicaciones en general, y el servicio telefónico de larga distancia, en particular. Es una buena cosa que el proyecto contemple para la radiodifusión televisiva una idea de servicios “intermedios” amplia, como la que establece la legislación de telecomunicaciones.

Ésta es una manera de aprovechar, respecto de la radiodifusión televisiva, las posibilidades de convergencia entre distintos servicios de telecomunicaciones que permite la tecnología digital ${ }^{10}$. El proyecto habla de concesiones de servicios "intermedios": "para la transmisión de señales de radiodifusión televisiva digital terrestre”, pero luego aclara que esta referencia a la radiodifusión televisiva no altera "la naturaleza legal del servicio intermedio en cuanto a su aptitud para proveer múlti-

${ }^{10} \mathrm{Al}$ respecto se han planteado dudas sobre esta disposición del proyecto, relativa al procedimiento de entrega de las concesiones de servicios "intermedios": "El proyecto técnico [con que se acompañe la solicitud de estas concesiones], además de las menciones y exigencias contempladas en el artículo $15^{\circ}$ de la ley $\mathrm{N}^{\circ} 18.168$, deberá contener un estudio especial que dé cuenta de cómo se garantizará la mayor eficiencia posible en el uso efectivo del espectro radioeléctrico asignado por la concesión... El Plan de Radiodifusión Televisiva establecerá los parámetros fundamentales de eficiencia espectral para estos servicios”. Aquí las dudas se relacionan con la discrecionalidad que podría tener el regulador al evaluar la "mayor eficiencia posible" en el uso del espectro que garantiza cada solicitante, aun cuando se encomiende al Plan de Radiodifusión Televisiva el establecimiento de los parámetros fundamentales al efecto. Mediante esa discrecionalidad se podría imponer un modelo específico para los operadores de televisión digital, contrariando en la práctica lo expresado por el Mensaje de este proyecto, en el sentido de que “...el proyecto no persigue imponer un modelo de operación específico para los operadores de Televisión Digital. En consecuencia, cada concesionario podrá ofrecer además del conjunto de sus contenidos, distintas alternativas tales como alta definición, multiprogramación, movilidad y/o portabilidad”. Sobre estas dudas, ver la presentación del Colegio de Ingenieros de Chile A. G. (2008). 
ples prestaciones”. Un ejemplo aquí podría ser la posibilidad de que junto a una o más señales televisivas se puedan transmitir datos. Con esto se reconoce la convergencia, pero el proyecto tiene a bien agregar que será de la "esencia" de estas concesiones de servicios "intermedios”: "su utilización principal en la transmisión de señales televisivas”. Quizás en esto último el proyecto se equivoca, al imponerles un servicio específico "esencial" a estos concesionarios y no dejar explícitamente abierto el campo de los servicios que se pueden intermediar, sin uno "esencial”. En esto último parece colarse la antigua lógica divergente con que se han regulado históricamente las telecomunicaciones, distinguiendo entre servicios específicos ${ }^{11}$. Tampoco parece muy funcional a la convergencia el hecho de que el proyecto exija que por cada nueva señal que una concesionaria de radiodifusión quiera emitir gracias a su concesión de servicios "intermedios", el concesionario deba pedir una nueva concesión de radiodifusión. Es sabido que la tecnología digital permite emitir más de una señal televisiva en el mismo espectro en que hoy puede emitirse sólo una señal. Mejor parecería una regulación en que se entregue una concesión de radiodifusión televisiva y que ésta le permita emitir todas las señales que la respectiva concesionaria pueda ${ }^{12}$.

Con todo, éste es un paso adelante hacia la convergencia: se abre la posibilidad de que las concesionarias de televisión puedan intermediar otros servicios de telecomunicaciones, y que la radiodifusión televisiva pueda ser transportada por concesionarios que puedan, a su vez, intermediar otros servicios. La convergencia se materializa en la medida en que la radiodifusión televisiva se conecta a otros servicios de telecomunicaciones, en la medida en que la legislación de televisión y la de telecomunicaciones se acercan mutuamente.

Esto parece ser una buena noticia para las concesionarias vigentes, pues, por el ministerio de la ley, van a quedar jurídicamente habilitadas para intermediar servicios de telecomunicaciones, incluidas otras señales televisivas. Y parece una buena noticia también para la audien-

${ }^{11}$ Sobre la inercia divergente en la historia de la regulación de las telecomunicaciones en Chile, puede verse Sierra (2008).

12 La dificultad que implica tener que pedir al CNTV una concesión de radiodifusión televisiva por cada nueva señal que se quiera emitir está relacionada con la dificultad más general que implica el mantener la idea de concesión de radiodifusión en el negocio televisivo digital y no quedarse, simplemente, con las concesiones de servicios "intermedios” que se proponen. Al respecto, véase supra p. 140. 
cia, por la posibilidad de más contenidos televisivos, pues distintos productores de este contenido podrán difundirlo sin tener que afrontar el desafío económico que implica montar una red y hundir su costo.

\section{5. ¿Qué hacer con las actuales concesiones de duración indefinida?}

Un punto muy importante en esta reforma es lo que se va a hacer con las concesiones vigentes. Como se apuntó más arriba, el proyecto transforma las concesiones vigentes en las dos concesiones que introduce: radiodifusión y servicios “intermedios”. A ambas les asigna una duración de 20 años. Llama la atención este plazo, pues las concesiones de radiodifusión televisiva que se entregan hoy duran 25 años. Se redujo en 5 años. ¿'Por qué? Además, según la legislación de telecomunicaciones, las concesiones de servicios "intermedios” duran 30 años. ¿Por qué las que se asocian a la radiodifusión televisiva se acortan en 10 años? Esta diferencia de plazo parece poco convergente, al distinguir, desde el punto de vista de su duración, entre concesiones de servicios "intermedios".

Ahora bien, el proyecto propone que las concesionarias que hoy califican como "nacionales" serán acreedoras de concesiones de servicios "intermedios" en todas las zonas de servicio de Chile. Esto beneficiará especialmente a aquellas concesionarias que hoy, siendo "nacionales", no tienen concesiones de radiodifusión televisiva sobre todas las áreas de servicio que hay en Chile. Éste es el caso, por ejemplo, de la Universidad de Chile y de Chilevisión. Hoy la Universidad de Chile no tiene concesión sobre Tongoy, por ejemplo, donde sí tiene Chilevisión. Pero esta última no tiene sobre Santiago, donde sí tiene la Universidad de Chile, que Chilevisión usufructa. Si el proyecto se convierte en ley, la Universidad de Chile, como concesionaria "nacional", será automáticamente titular de una concesión de servicios "intermedios” en Tongoy, y Chilevisión, por su parte, tendrá automáticamente la suya en Santiago ${ }^{13}$.

${ }^{13}$ Esto hace plantearse una pregunta sobre el acuerdo de usufructo entre la Universidad de Chile y Chilevisión. Este acuerdo vence en 2018. Si el proyecto se convierte en ley, Chilevisión ganará espectro sobre lugares en que hoy no tiene, y a los que accede usufructuando de las concesiones de la Universidad de Chile. Al ganar concesiones propias, el incentivo para este usufructo puede desaparecer. 
Como se sabe, el régimen concesional de la radiodifusión televisiva vigente en Chile es problemático, pues es diferenciado: un grupo de concesiones tiene duración indefinida y otro grupo tiene una duración de 25 años. Esta diferencia es un desafío para cualquier reforma que busca enfrentar el cambio digital. Se deben contraponer dos objetivos que, en cierto punto, pueden entrar en tensión recíproca: el respeto de derechos adquiridos, por una parte, y obtener la máxima eficiencia posible en el uso del espectro radioeléctrico. ¿Cómo enfrenta el proyecto de ley este desafío?

En principio, lo enfrenta correctamente. Reconoce que las condiciones indefinidas son un permiso de uso de que gozan sus titulares indefinidamente. Esto implica reconocer que las concesiones de radiodifusión televisiva vigentes son un título para emitir contenidos televisivos a través del espectro, pero que no son un título sobre una determinada cantidad de espectro. De esta forma, no se les reconoce un derecho indefinido temporalmente sobre los $6 \mathrm{MHz}$ que usan hoy, sino el que sea necesario para emitir una señal. Bien, pero la forma en que el proyecto de ley materializa este razonable criterio general admite críticas, pues parece imprecisa. Veámoslo en el siguiente ejemplo.

UC-TV tiene una concesión de radiodifusión televisiva en la zona de servicio de Santiago, que es indefinida en el tiempo. Si el proyecto se convierte en ley, esta concesión se transformará en dos concesiones: una de radiodifusión televisiva de libre recepción (que formará parte de una "nacional” por la actual cobertura geográfica de UC-TV) y una concesión de servicios "intermedios" sobre la zona de servicio de Santiago. Según el proyecto, ambas duran 20 años. Al cabo de estos 20 años, UC-TV tiene la posibilidad de renovar ambas por otros 20 años. Si decide no hacerlo, el proyecto de ley recuerda el hecho de que UC-TV era titular de una concesión de radiodifusión indefinida en el tiempo y le da derecho a que el regulador televisivo (CNTV) le provea de los "medios indispensables" para seguir emitiendo en forma indefinida en el tiempo "una señal televisiva digital de calidad consistente con las condiciones tecnológicas del mercado televisivo”.

En otras palabras, a las actuales concesionarias el proyecto les reconoce el derecho que hoy tienen a transmitir una señal televisiva indefinidamente en el tiempo, y también les reconoce el espectro que sea necesario para transmitirla. Esto último es a lo que el proyecto se refiere como "medio indispensable" para emitir. Si las condiciones 
tecnológicas del mercado televisivo en el futuro determinan una calidad de señal que puede lograrse con $1 \mathrm{MHz}$ o con menos, ésta será la cantidad de espectro (el "medio indispensable") que la concesionaria tendrá derecho a seguir usando indefinidamente en el tiempo. Así el proyecto busca conciliar el respeto de derechos adquiridos con la máxima eficiencia posible en el uso del espectro radioeléctrico ${ }^{14}$.

Si bien este mecanismo refleja un criterio correcto respecto del carácter de las concesiones (que son permisos de uso de un recurso, permisos sobre los que se tiene propiedad, pero ésta no alcanza al recurso mismo), la forma de ponerlo en práctica podría ser mejorada. Respecto de las actuales concesiones indefinidas, el proyecto dispone que si al cabo del plazo de 20 años no hay renovación de las dos nuevas concesiones en que las actuales concesiones indefinidas se transforman, nace un derecho para sus titulares de obtener del CNTV "medios indispensables" a objeto de seguir transmitiendo indefinidamente una señal. Esta redacción parece problemática: ¿Qué son "medios indispensables” sino espectro radioeléctrico? ¿Por qué no decirlo más claramente? Si es espectro radioeléctrico, ¿por qué el proyecto menciona sólo al CNTV y no a la Subtel, que tiene el mandato legal de administrar el espectro? ¿Por qué diferir 20 años la resolución del problema que constituye la indefinición temporal de algunas concesiones, con la incertidumbre que esto puede conllevar? Y un par de preguntas más: si una concesionaria no renueva sus concesiones, ¿̇se le dará concesión de servicios "intermedios" respecto de los "medios indispensables”, o éstos se le darán bajo otra modalidad? Si es esto último, ¿̇bajo cuál modalidad?

Mejor parecería un mecanismo que resuelva esta cuestión ahora, de una manera clara y expedita. Una manera clara y expedita debería involucrar una manifestación de voluntad por parte de los titulares de

${ }^{14}$ Cabe notar que, de materializarse esta hipótesis de no renovación por parte de los actuales titulares de concesiones indefinidas en el tiempo, el derecho que les nacerá a que el CNTV los provea de los “medios indispensables” para emitir una señal será sólo respecto de las concesiones que actualmente tienen y no de la de radiodifusión que ganaron sobre nuevos territorios como consecuencia de transformarse en titulares de una concesión de radiodifusión "nacional”. Así, por ejemplo, si la Universidad de Chile decide no renovar por otros 20 años sus nuevas concesiones, tendrá derecho a que el CNTV le provea los "medios indispensables" para seguir con la posibilidad de emitir una señal en Santiago, donde es concesionaria hoy, pero no en Tongoy, porque hoy no lo es en esa localidad de la IV Región. 
concesiones indefinidas. Estos titulares podrían ser presentados con la siguiente alternativa:

1. Si quieren mantener el carácter indefinido de su derecho a trasmitir una señal televisiva, muy bien, se les ofrece un multiplex (cuya administración debe definirse), para que la sigan emitiendo en el espectro radioeléctrico estrictamente necesario. $\mathrm{O}$ bien:

2. Si quieren más espectro radioeléctrico para, en la forma de una concesión de servicios “intermedios”, poder transmitir más de una señal televisiva, así como para ofrecer otras aplicaciones u otros servicios, bien, pero deben renunciar formalmente al carácter temporal indefinido de sus actuales concesiones. Hecho esto, se les dan las dos concesiones que contempla el proyecto (de radiodifusión y de servicios "intermedios") por 20 años renovables (o por el tiempo que finalmente se decida para estas concesiones $)^{15}$.

\subsection{El plazo para migrar}

El proyecto es algo equívoco respecto del camino a seguir hacia la televisión digital y el denominado "apagón analógico" que marca el fin de este camino. El proyecto lo regula como sigue. Los titulares de concesiones de radiodifusión televisiva vigentes a la fecha de entrada en vigencia de la ley, sea en la banda VHF o en la banda UHF, deberán:

- Lograr una "cobertura digital de al menos un $85 \%$ de la población comprendida en su zona de servicio”, dentro del plazo de cinco años contados a partir de la fecha de vigencia de la ley;

- Lograr una "cobertura digital de un $100 \%$ de su zona de servicio”, dentro del plazo de ocho años contados desde la fecha de vigencia de la ley.

En principio, entonces, el "apagón analógico" debe producirse a los ocho años de la entrada en vigencia de la ley. Excepcionalmente, este plazo puede extenderse por decreto supremo en casos justificados. $141-144)$.

${ }^{15}$ Para una mejor descripción y fundamento de esta alternativa, ver Sierra (2006: 
Este calendario plantea algunas preguntas. Ellas no se refieren a la extensión de cinco y ocho años. Ésta es una cuestión prudencial que en este caso, atendidas las circunstancias de Chile y la experiencia comparada, puede ser perfectamente razonable. Las preguntas, más bien, tienen que ver con ciertas dificultades de interpretación. Primera: dentro de los primeros cinco años se debe cubrir con radiodifusión televisiva digital el 85\% de la población "comprendida en su zona de servicio”. ¿Cuál “zona de servicio”? ¿Las originales que la concesionaria tenía en virtud de sus concesiones analógicas? ¿O, además, las nuevas que adquirió en virtud de la concesión "nacional" a que se hizo acreedora con la nueva ley? Segunda: ¿Por qué para el plazo de los cinco años se usa un criterio demográfico (85\% de la "población”) y para el plazo de ocho años uno geográfico (100\% de su "zona de servicio")?

Ahora bien, y también en relación con este calendario, y como lo sugiere la experiencia comparada, el proyecto propone una modalidad de simulcasting durante el período de transición. Esto es, los concesionarios siguen transmitiendo su señal analógica y la reproducen en digital. Con todo, cabe puntualizar que los concesionarios actuales, que califiquen como titulares de concesiones nacionales y regionales, se verán beneficiados, por el ministerio de la ley, con una concesión de servicios "intermedios" y con una de radiodifusión televisiva para una señal digital. Si quieren emitir otras señales digitales, deberán pedir concesiones de radiodifusión extras al CNTV.

$\mathrm{Y}$ un último punto. ¿Cuándo se termina la posibilidad de pedir una concesión de radiodifusión televisiva analógica en la banda VHF? ${ }^{16}$ ¿Desde la entrada en vigencia de la ley? ¿Desde el momento del “apagón analógico”? Esto debería definirse explícitamente.

Con todas estas preguntas y dudas, la propuesta principal que hace el proyecto en el sentido de aplicar la categoría concesional de servicios "intermedios" de telecomunicaciones a la radiodifusión televisiva es un avance importante. Sin embargo, esto que es un avance para el sistema televisivo en general implica un riesgo de retroceso en el caso de un operador televisivo en particular: TVN.

${ }^{16}$ Desde el año 2000 la banda UHF está congelada para nuevas concesiones de radiodifusión televisiva. Sólo la banda VHF está abierta a ellas, en las zonas de servicio que no están saturadas, obviamente. 


\section{LA REFORMA DE LA LEY 19.132, SOBRE TVN}

El proyecto de ley que se refiere al radiodifusor televisivo estatal (TVN) es lo más discutible de esta reforma legislativa. Esto, pues por distintas vías difumina el giro de esta empresa pública, expandiéndolo al punto de echar una sombra de duda sobre el criterio de subsidiariedad estatal que viene inspirando nuestra regulación económica desde hace décadas. Al difuminar y expandir este giro, se abre la puerta para que el Estado ingrese como proveedor de servicios al mercado de las telecomunicaciones, un mercado que, como sabemos, puede ser servido bien por distintos operadores privados. De aquí que este proyecto se aparte, injustificadamente, del criterio de subsidiariedad estatal que desde hace años viene orientando nuestra regulación económica.

Como sabemos, el criterio de subsidiariedad se expresa en la idea de que, por regla general, los bienes y servicios de la sociedad sean provistos por las personas privadas. Sólo en casos excepcionales, cuando los privados no quieran o no puedan proveerlos, los provee el Estado. Esto no impide, por supuesto, que el Estado ingrese a la economía de una manera indirecta, otorgando subsidios, por ejemplo. Lo que el criterio de subsidiariedad desalienta es su ingreso como empresario, como es el caso de TVN en el mercado de la radiodifusión televisiva y, con este proyecto de ley, en el mercado audiovisual y en el de las telecomunicaciones, en genera ${ }^{17}$.

Además, el proyecto rompe el pie de igualdad con el resto de los radiodifusores televisivos en que TVN fue puesto por la Ley 19.132 en 1992. Esto lo hace al abrir la posibilidad de que TVN reciba directamente recursos desde el Estado. ¿’Por qué se cambia hoy, a las puertas de esta importante innovación tecnológica, el criterio de igualdad que $\tan$ trabajosamente fue legislado en 1992, y que le ha permitido a TVN ganar autonomía del Gobierno y del sistema político al no depender de los recursos que éstos quieran entregarle? Este trabajo deja, simplemente, planteada esta pregunta, para concentrarse en otras propuestas de esta reforma.

${ }^{17}$ El criterio de subsidiariedad está relacionado con el artículo 19 número 21 de la Constitución Política, que exige una ley de quórum calificado cuando el Estado quiera desarrollar o participar en actividades empresariales, en circunstancias de que para que los particulares las emprendan no se necesita autorización especial alguna: tienen el campo abierto. Si el Estado no cuenta con esa calificada autorización, no puede pisar la economía como empresario. 
El proyecto originalmente redactado por el Gobierno ha experimentado algunas modificaciones en su paso por la Comisión de Ciencias y Tecnología de la Cámara de Diputados, que fueron acordadas con el Gobierno. Al momento de escribir estas líneas, el proyecto aprobado por dicha comisión está en discusión en la Sala de la Cámara de Diputados. En lo que sigue, y cuando corresponda, se hará referencia a la propuesta original del Gobierno y a su modificación durante el trámite legislativo hasta ahora.

Básicamente, este trabajo sostiene que el proyecto de ley autoriza al Estado para desarrollar actividades empresariales en mercados en los cuales los privados pueden y quieren proveer los bienes que se necesitan. No hay buenas razones para que el Estado ingrese a proveerlos él. El proyecto, al menos, no da ninguna y, no obstante, abre la capacidad empresarial del Estado de un modo excesivo e injustificado. Lo hace por dos vías, al menos. Una es la expansión y ambigüedad que introduce al giro empresarial de TV. La otra es la entrega a TVN de la misma concesión de servicios "intermedios" que, según se vio más arriba, el otro proyecto de ley les entrega a todos los actuales concesionarios de radiodifusión televisiva. En el futuro digital, esto permitiría a TVN prestar los demás servicios de telecomunicaciones que dichas autorizaciones permiten. ¿¿Queremos que también el Estado provea estos servicios como empresario? Ésta es una pregunta que el debate legislativo que comienza no puede eludir, pues así se lo exige el criterio de subsidiariedad. A continuación se revisan las dos vías mediante las cuales el proyecto abre la puerta al Estado empresario. Luego se plantean algunas dudas sobre la corrección de quebrar el pie de igualdad que hoy existe entre la televisión estatal y la privada.

\subsection{Un giro empresarial expansivo y difuso}

En su Art. 2, la ley vigente sobre TVN fija así su giro: "Su objeto es establecer, operar y explotar servicios de televisión”. Y agrega: "En general, podrá realizar todas las actividades propias de una concesionaria de servicios de televisión constituida como persona jurídica de derecho privado, con iguales derechos, obligaciones y limitaciones".

El giro de TVN como empresa pública fue una cuestión debatida durante la discusión de esta ley entre 1990 y 1992. Al final, se decidió 
esta redacción, que enfatiza la idea de “servicios de televisión” y la idea de que debe actuar en un pie de igualdad con las demás concesionarias de radiodifusión televisiva. Poco más adelante, la ley le impone a TVN una obligación al contenido que emita en el sentido de que en él debe manifestarse "pluralismo" y "objetividad", en especial cuando se trata de "noticieros, programas de análisis o debate político".

Esta definición del giro de TVN es bastante parecida a la que la primera ley de televisión, la Ley 17.377 de 1970, daba a la recién creada TVN: "El objeto será establecer, operar y explotar un sistema nacional de televisión destinado a transmitir, a través del territorio nacional, programas audiovisuales, entendiéndose por tales todo sistema que permita la transmisión de imágenes y sonidos mediante sistemas ópticos o electromagnéticos. La Empresa podrá realizar todas las actividades, negocios, operaciones, actos, contratos y convenciones que se relacionen con su objeto” (Art. 14 de la Ley 17.377 de 1970).

El proyecto de ley que aquí se analiza, sin embargo, propone un giro para TVN harto más amplio y ambiguo. En su redacción original, el proyecto dijo: "Su objeto es establecer, operar y explotar servicios de emisión de señales de televisión, servicio de transporte de señales televisivas digitales por ondas terrestres y otras actividades audiovisuales, tales como producción cinematográfica, radiodifusión, internet y producción discográfica”. Y a continuación agrega, como inciso segundo, que TVN "podrá realizar todas las actividades propias de una empresa privada de servicios audiovisuales, con iguales derechos, obligaciones y limitaciones" (énfasis agregado).

El texto aprobado por la Comisión de Ciencia y Tecnología modifica el inciso primero. En lugar de precisar su amplitud, la extiende aún más: "Su objeto es establecer, operar y explotar servicios de producción, emisión y transmisión de contenidos audiovisuales, cualquiera sea su formato, plataforma o medio" (énfasis agregado). Ya ni siquiera hay referencia a la radiodifusión televisiva, como en la redacción original, sino que a la harto más extensa idea de "contenidos audiovisuales”.

El inciso segundo de la redacción se mantiene. Este inciso, al establecer la cláusula de igualdad con los otros operadores, también difumina el giro de la empresa. En la ley vigente esta cláusula de igualdad es más acotada: “[TVN] podrá realizar todas las actividades propias de una concesionaria de servicios de televisión constituida como persona jurídica de derecho privado, con iguales derechos, obli- 
gaciones y limitaciones” (énfasis agregados). El proyecto, en cambio, equipara el giro de esta empresa pública desde el de concesionaria de radiodifusión televisiva a uno propio de una "empresa privada de servicios audiovisuales”. La extensión es patente.

$\dot{ }$ Se quiere que el Estado tenga una empresa dedicada a producir películas para el cine? ¿La vuelta de Chile Films? Por su parte, una empresa proveedora de internet (ISP, Internet Service Provider) puede ser considerada como prestadora de servicios audiovisuales. ¿Queremos a TVN, al Estado, a fin de cuentas, como ISP? Hoy TVN tiene un portal en internet (www.tvn.cl) donde, entre otras cosas, se puede recibir su señal en vivo. $\dot{¿}$ El proyecto quiere formalizar en la ley esto o quiere otra cosa más? Habría que precisarlo explícitamente. En el mismo sentido, la producción de DVD puede también ser entendida como la prestación de un servicio audiovisual. ¿Queremos que el Estado, a través de TVN, se transforme en sello discográfico? Hoy TVN pone en el mercado a través de distribuidores privados DVD con algunos de sus programas, bajo el sello de $\mathrm{TVN}^{18}$. ¿Esto es lo que el proyecto quiere formalizar legislativamente? ¿O quiere algo más? También sería bueno precisarlo, porque podríamos terminar con el Estado como productor discográfico. Esto sería un evidente retroceso al Estado empresario en estas materias.

La ambigüedad en el giro de TVN como empresa pública, que el proyecto introduce, se ve agravada por un concepto que el mismo proyecto adscribe a ese giro: el "bien común". En su redacción original, el proyecto decía: “Televisión Nacional de Chile está al servicio del bien común”. El texto aprobado por la Comisión de Ciencia y Tecnología modificó así esta redacción: “Se reconoce en Televisión Nacional de Chile un rol diferenciador, en virtud del cual su servicio estará orientado principalmente a satisfacer el bien común...”.

¿Una empresa pública cuyo giro es el "bien común”? Con este concepto el giro de TVN termina por difuminarse. Es difícil haber pensado aquí en un concepto menos afortunado. Por distintas razones. Algunas son abstractas y tienen que ver con el hecho de que este concepto se originó en un contexto político y cultural previo a la edad moderna, es medieval. Esto mismo, creo, hace que sea un ideal público

\footnotetext{
${ }^{18}$ Por ejemplo, "El Señor de la Querencia”, que se distribuye a través de la Feria del Disco. Ver http://www.feriadeldisco.cl/cgi-bin/wspd_cgi.sh/WService=wsPFDD/ MIXinterior_pelicula.htm?pr_partID=000000404348
} 
un tanto refractario al liberalismo y a la aspiración de vivir en una sociedad plural, en la cual, provisto un cierto orden que se considera correcto, se admiten distintas concepciones del bien o de lo bueno. No es éste el lugar, sin embargo, para fundamentar estas afirmaciones. Solamente diré que el concepto de "bien común" no es afortunado como giro de una empresa pública, porque es extremadamente amplio y vago. Por su propiedad y por el hecho de competir en el mercado, las empresas públicas deben tener un giro lo más preciso y acotado posible, para saber lo más exactamente posible qué pueden y qué no pueden hacer ${ }^{19}$. El concepto de "bien común" no cumple con esta exigencia. No puede cumplirla, mejor dicho.

Para comprobar su ambigüedad, se puede leer la referencia que al "bien común" hace la Constitución vigente. Esta referencia viene del texto original de la Constitución de 1980. Ésta es la primera Constitución que en la historia de Chile menciona el concepto de "bien común”. Así son sus términos:

El Estado está al servicio de la persona humana y su finalidad es promover el bien común, para lo cual debe contribuir a crear las condiciones sociales que permitan a todos y a cada uno de los integrantes de la comunidad nacional su mayor realización espiritual y material posible, con pleno respeto a los derechos y garantías que esta Constitución establece. (Art. 1, énfasis agregado).

Podría decirse, entonces, que a TVN se le está imponiendo la tarea de colaborar a crear las condiciones sociales que nos permitan, a todos y cada uno de los chilenos, y en la mayor medida posible, realizarnos espiritual y materialmente. ¿Cómo hace esto un radiodifusor televisivo del Estado organizado como empresa pública? La imaginación parece no tener límites aquí.

Este carácter ilimitado del concepto "bien común” puede advertirse en el propio proyecto de ley. Luego de ponérselo a TVN como giro, el proyecto enuncia una serie de tareas que ayudarían a alcanzar tan alto ideal. Muchas de ellas también son extremadamente vagas y

${ }^{19}$ Sobre la importancia de que el Estado empresario tenga giros precisos y bien definidos, es interesante el fallo de la Corte Suprema en el año 2000, pronunciado en el recurso de amparo económico Asociación Nacional de la Prensa Asociación Gremial y otro con Empresa de Transporte de Pasajeros Metro Sociedad Anónima. 
algunas distintas entre sí. Por ejemplo, según la primera redacción del proyecto, TVN debe "fomentar el pluralismo y el desarrollo cultural, ofreciendo una amplia variedad de programas, de alta calidad”. La redacción aprobada por la Comisión de Ciencia y Tecnología no reduce esta ejemplificación del "bien común”, sino que la amplía, pues TVN debe "Fomentar el enriquecimiento cultural de la sociedad chilena, ofreciendo una amplia variedad de programas, de alta calidad, que revelen información y estimulen el conocimiento sobre civilizaciones y culturas nacionales y extranjeras, procesos creativos y artísticos, corrientes de pensamiento, y sobre los avances científicos y tecnológicos, entre otros". También, de acuerdo al texto aprobado por la Comisión de Ciencia y Tecnología, debe "promover y respetar los valores democráticos, los principios y los derechos establecidos en la Constitución y en los tratados internacionales sobre derechos humanos, ratificados por Chile y que se encuentren vigentes, así como fomentar la formación cívica, la información, formación y participación ciudadana”. Asimismo, según este mismo texto, debe "Promover el pluralismo, reconociendo la diversidad cultural, étnica, ideológica y religiosa, entre otras, especialmente los derechos de los pueblos originarios, como en general de todo grupo, tradición o cultura que con su particular forma de plantearse frente a la realidad, enriquezca los valores nacionales, la visión que cada ciudadano tiene de su país, y aquella que proyecta Chile dentro del continente y dentro de la comunidad internacional”. Y remata asignándole a TVN la tarea de "Promover la identidad de cada una de las regiones del país, generando las condiciones para una real integración regional, nacional e internacional, tanto a través de contenidos que representen las distintas realidades regionales, como de acciones que permitan la existencia y un grado de autonomía de canales regionales, donde les sea posible emitir, principalmente, programas e informativos locales, que desarrollen en sus contenidos o reportajes aspectos culturales propios de la zona o ámbito territorial de su señal, y cuya capacidad de cobertura abarque, a lo menos, a la totalidad de las provincias de la región”. Con esto último, el proyecto está predeterminando parte importante de la estructura y organización industrial de TVN, restándole a su gobierno corporativo la autonomía que requiere para tomar importantes decisiones estratégicas. Todo esto en nombre del "bien común". 
El mismo "bien común" se esgrime para un cierto proteccionismo cultural, al encomendársele a TVN "Fomentar el desarrollo de la industria audiovisual nacional, mediante contenidos producidos en el país que representen no menos del $40 \%$ del total de su programación”. El texto original contemplaba un guarismo más alto: 60\%. Es importante tener en cuenta que la producción de contenido televisivo ya está subsidiada en Chile a través de, por ejemplo, los fondos concursables del CNTV, el Fondo Audiovisual bajo el amparo del Consejo Nacional de la Cultura y las Artes, y los fondos especiales que establece la Ley de Prensa. Además de todos estos subsidios, y en nombre del "bien común", este proyecto quiere también subsidiar a la "industria audiovisual nacional” a través de la empresa pública TVN. Este nuevo subsidio a la industria, que se agrega a los fondos concursables que ya existen, parece un beneficio excesivo a un determinado sector de la economía. Parece, más bien, un ejemplo de "captura” regulatoria.

El concepto de "bien común” y sus ejemplificaciones, entonces, terminan por difuminar el giro de TVN, el que ya venía bastante diluido por la definición que el proyecto da primero en el sentido de que esta empresa pública, además de servicios televisivos, puede dedicarse a establecer, operar y explotar servicios de producción, emisión y transmisión de "contenidos audiovisuales". La amplitud y ambigüedad que estas definiciones introducen en el giro de TVN se ve agravada, también, por otra disposición que el proyecto propone en concordancia con la reforma a la ley general de televisión vista más arriba, en el sentido de introducir la categoría de servicios "intermedios” a la radiodifusión televisiva.

\section{2. ¿El Estado como empresario de telecomunicaciones?}

Como se vio más arriba, el proyecto que busca reformar la Ley 18.838 introduce, entre sus principales innovaciones, la categoría concesional de servicio "intermedio" de telecomunicaciones a la radiodifusión televisiva. Ese proyecto dispone que esta concesión de servicios "intermedios" debe estar "esencialmente" destinada al transporte de emisiones televisivas digitales terrestres, pero también dispone que dicha concesión está abierta, además, a las múltiples prestaciones que se pueden proveer con una concesión de servicio “intermedio" de teleco- 
municaciones ${ }^{20}$. Vale la pena recordar aquí la amplitud con que la Ley 18.168, General de Telecomunicaciones, define a estos servicios "intermedios":

Servicios intermedios de telecomunicaciones, constituidos por los servicios prestados por terceros, a través de instalaciones y redes, destinados a satisfacer las necesidades de transmisión o conmutación de los concesionarios o permisionarios de telecomunicaciones en general, o a prestar servicio telefónico de larga distancia a la comunidad en general.

Es decir, un concesionario de servicios "intermedios" de telecomunicaciones está abierto a la posibilidad de satisfacer las necesidades de transmisión o conmutación de los concesionarios o permisionarios de telecomunicaciones en general, incluyendo servicio telefónico de larga distancia.

El proyecto de ley que busca reformar la Ley 18.838 procura, con razón a mi juicio, dar esta amplitud a la radiodifusión televisiva, a fin de facilitar el proceso de convergencia que posibilita la tecnología digital. Introduciendo la categoría de servicio "intermedio" a la radiodifusión televisiva digital, lo que se quiere es precisamente esto: posibilitar a los operadores de televisión abierta su incursión en otros terrenos de las telecomunicaciones en general. Esto está muy bien y en concordancia con el desarrollo tecnológico. La pregunta que surge, sin embargo, es si queremos que el Estado se expanda a estos nuevos negocios a través de TVN.

Hasta ahora, la reforma legislativa propuesta por el Gobierno mediante los dos proyectos de ley que este trabajo comenta sugiere contestar que sí. Esto, pues a TVN se le dan las mismas concesiones de radiodifusión televisiva y, lo más importante aquí, de servicios "intermedios” de telecomunicaciones que se le dan al resto de los operadores televisivos, sin calificación alguna. Además, el proyecto de ley sobre TVN establece que en su giro se incluye el "transporte" de señales (lo que alude claramente a la nueva concesión de servicios

${ }^{20}$ Vale la pena recordar la amplitud de la definición que la Ley 18.168, General de Telecomunicaciones, da a estos servicios: "Servicios intermedios de telecomunicaciones, constituidos por los servicios prestados por terceros, a través de instalaciones y redes, destinados a satisfacer las necesidades de transmisión o conmutación de los concesionarios o permisionarios de telecomunicaciones en general, o a prestar servicio telefónico de larga distancia a la comunidad en general”. 
“intermedios”), agregando una cláusula de igualdad con los otros operadores televisivos. Como se vio más arriba, esta cláusula de igualdad es bastante más amplia que la que existe hoy. Ésta permite a TVN hacer lo mismo que puede hacer cualquier "concesionaria de servicios de televisión”. El proyecto propone permitirle hacer lo mismo que cualquier "empresa privada de servicios audiovisuales". La expansión es patente. Y de nuevo la pregunta ineludible: ¿queremos semejante expansión empresarial del Estado por medio de TVN?

\subsection{Sobre la prudencia de diferenciar ahora, sin saber cómo operará la TV digital, la televisión estatal y la privada}

Por último, algunas palabras sobre otra propuesta también muy discutible de este proyecto. Uno de los criterios más trabajosamente discutidos y acordados durante la tramitación de la Ley 19.132 fue el pie de igualdad en que quedaron TVN y el resto de los radiodifusores televisivos $^{21}$. La única diferencia relevante es la obligación a la que fue sometida TVN en el sentido de que "el pluralismo y la objetividad deberán manifestarse en toda su programación y, muy especialmente, en los noticieros, programas de análisis o debate político.” Ésta es una obligación calificada de pluralismo, pero no hay que olvidar que dentro del estándar de "correcto funcionamiento" al que están sometidos todos los radiodifusores televisivos, la noción de "pluralismo" también está incluida. Es decir, la específica obligación de ser pluralista que recae en TVN no es demasiado distinta de la que recae sobre todos los demás radiodifusores televisivos. Esta igualdad básica entre todos los radiodifusores televisivos resulta reforzada por la prohibición de recibir recursos fiscales especiales que la ley impuso a TVN. Así lo dispone el Art. 25 de la Ley 19.132: “Televisión Nacional de Chile, en caso alguno, podrá comprometer el crédito público. Tampoco podrá obtener financiamientos, créditos, aportes, subsidios, fianzas o garantías del Estado o de cualesquiera de sus organismos, entidades o empresas, sino en los casos en que ello fuere posible para el sector privado y en iguales condiciones”. El correlato lógico de esta prohibición es un giro empresarial definido en analogía con los demás radiodifusores televisi-

${ }^{21}$ Para el proceso de reforma que llevó a las leyes 19.131 y 19.132 en 1992, ver Sierra (2201). 
vos: "Su objeto es establecer, operar y explotar servicios de televisión. En general, podrá realizar todas las actividades propias de una concesionaria de servicios de televisión constituida como persona jurídica de derecho privado, con iguales derechos, obligaciones y limitaciones" (Art. 2 de la Ley 19.132).

El proyecto invierte el pie de igualdad vigente. Lo hace, por un lado, al imponerle a TVN tareas generales y específicas y, por otro, al permitir que reciba aportes fiscales directos: “Asimismo, la empresa, para el cumplimiento de sus fines relativos al bien común referidos en el artículo $3^{\circ}$ de esta ley, podrá solicitar y recibir recursos fiscales y de instituciones públicas facultadas para promover a través de financiamiento iniciativas al respecto". Y también invierte el criterio abriendo a TVN el aval del Estado. Hasta hoy, la ley dispone: “Televisión Nacional de Chile, en caso alguno, podrá comprometer el crédito público. Tampoco podrá obtener financiamientos, créditos, aportes, subsidios, fianzas o garantías del Estado o de cualesquiera de sus organismos, entidades o empresas, sino en los casos en que ello fuere posible para el sector privado y en iguales condiciones”. El proyecto, en cambio, dispone: "No obstante, podrá comprometer la contratación de créditos, previa autorización del Ministerio de Hacienda, mediante decreto dictado bajo la modalidad establecida en el inciso cuarto del artículo 11 de la Ley No 18.196”.

No se ven razones para modificar el pie de igualdad que hoy existe entre la radiodifusión televisiva privada y la estatal. Al contrario, el propio canal ha reconocido que del hecho de que su presupuesto no dependa de decisiones fiscales, sino que de la misma fuente de ingresos que tienen los radiodifusores privados, se ha derivado una mayor autonomía del canal estatal frente al sistema político ${ }^{22}$. Además, el proyecto busca introducir este cambio radical de criterio al tiempo que expande y difumina el giro empresarial de TVN y, más encima, cuando se está a las puertas de una innovación tecnológica que, como la digitalización,

${ }^{22}$ Respecto a las relaciones entre TVN y el sistema político, sólo cabe celebrar la propuesta del proyecto en el sentido de que las sesiones en que el Senado se pronuncia sobre las sugerencias que hace la Presidencia de la República para el directorio del canal estatal, sean públicas y no secretas como, increíblemente, han sido hasta ahora por disposición de la ley. Y, al mismo tiempo, sólo cabe sorprenderse por el hecho de que el proyecto relativo a la Ley 18.838 no contemple lo mismo respecto de las sesiones en que secretamente se analizan los nombres para el CNTV. 
augura formas de televisión que hoy no es posible prever. ¿No sería más sensato esperar a que se desarrolle un poco la televisión digital entre nosotros, a fin de tener más información para decidir sobre TVN y los criterios que la rigen?

\section{CONCLUSIONES}

La reforma de la legislación televisiva que el Gobierno ha iniciado parece dar un paso adelante, pero, lamentablemente, otro atrás. El paso adelante está dado por la introducción de la categoría de servicio “intermedio" en la radiodifusión televisiva, lo que la conecta a las telecomunicaciones, en general, y apunta en el sentido de la "convergencia” en que se despliega el desarrollo tecnológico. También da un paso adelante al reconocer que las concesiones de radiodifusión televisiva son permisos de uso de un recurso público, como es el espectro radioeléctrico. Sobre este permiso sus titulares tienen un derecho de propiedad, pero esta propiedad no alcanza al recurso propiamente tal. Por esto, el proyecto que modifica la Ley 18.838 está en lo correcto al no reconocer un supuesto derecho de los actuales concesionarios sobre los $6 \mathrm{MHz}$ que hoy usan, limitándose a reconocer que tienen un derecho a usarlo. ¿Cuánto espectro? El necesario para la emisión de una señal. Como se vio más arriba, la forma en que el proyecto concreta estas ideas no parece la mejor, porque es algo ambigua y precaria. No obstante, el criterio abstracto es correcto.

El paso atrás está dado por la resurrección de las "cadenas" televisivas que trae el proyecto que reforma la Ley 18.838, bajo el nombre más eufemístico de "campañas de utilidad o interés público". También se retrocede al darle poderes al regulador televisivo para decidir sobre la publicidad que puedan contratar las estaciones al emitir ciertos programas. Se retrocede, pues se aumenta el poder de la autoridad sobre el contenido televisivo, amenazando la libertad en un doble sentido, como libertad de expresión y como libertad económica.

Y otro importante paso atrás está dado por el proyecto que modifica la Ley 19.132, sobre TVN. Por la vía de expandir y hacer más ambiguo el giro de esta empresa del Estado, y por la vía de concederle concesiones de servicios “intermedios” sin precisión o calificación alguna, este proyecto está abriendo la posibilidad de que el Estado ingrese como empresa al mercado audiovisual y al de las teleco- 
municaciones en general. En este caso, el criterio de subsidiariedad nos dice que esto es innecesario y, por tanto, es injustificable. El proyecto no hace esfuerzo alguno por convencernos de lo contrario.

Esta reforma legislativa sería más claramente un avance si en el proyecto que reforma la Ley 18.838 se eliminaran las “campañas de utilidad o interés público” y no se le entregara más poder al CNTV para regular la publicidad televisiva. Esto evitaría los riesgos constitucionales derivados de la amenaza a la autonomía editorial que esas "campañas" envuelven, y los derivados de la posibilidad de discriminación en contra de la publicidad televisiva que esta regulación conlleva. Eliminados estos distractores, el debate legislativo podría concentrarse en lo que el futuro digital exige y es verdaderamente importante: el régimen concesional mediante el cual se aprovecharán las ventajas de la tecnología digital acercando, en un sentido convergente, la radiodifusión televisiva al resto de las telecomunicaciones.

Por su parte, los impulsores del proyecto que reforma la Ley 19.132, sobre TVN, deberían empezar por dar razones de la expansión empresarial que se le está autorizando al Estado. Esto implica hacerse cargo de la extensión del nuevo giro empresarial que se le da a TVN, de la ambigua referencia al "bien común", de la entrega que se le hace de concesiones de servicios "intermedios", sin restricción ni calificación alguna, y del quiebre del pie de igualdad que ha existido entre TVN y el resto de los radiodifusores televisivos, al permitirse que la empresa estatal reciba aportes fiscales directos.

La futura llegada de la televisión digital, con la multiplicidad de señales que ella permite, abre una evidente oportunidad de evaluar la necesidad y corrección de tener una empresa como TVN, que convierte al Estado en radiodifusor televisivo. Por lo visto, el Gobierno no sólo ha decidido mantener TVN en la era digital, sino que ha apostado a su refuerzo y expansión.

Ya que parece haberse descartado la posibilidad de privatizar, mediante un procedimiento transparente y razonable, esta empresa pública, podrían al menos imaginarse modelos más interesantes de televisión pública para Chile. Ejemplos interesantes hay en el mundo. Una posibilidad es el modelo que ofrece Channel 4 en Gran Bretaña ${ }^{23}$. Se trata de una red pública que no produce sus contenidos, sino que los

${ }^{23}$ Ver http://www.channel4.com/about4/overview.html 
licita entre productoras independientes, favoreciendo la diversidad de dichos contenidos y la autonomía editorial del canal, pues carece de una estructura corporativa vertical que reproduzca y amplifique en el interior las influencias y presiones que provengan del exterior. Channel 4 se financia con publicidad, sobre un piso de ingresos que recibe anualmente del fisco.

Otra posibilidad la ofrece el modelo de la empresa estatal Kordia en Nueva Zelanda ${ }^{24}$, que sólo consiste en una infraestructura de red que el Estado ofrece a los más distintos productores de contenido televisivo. Es un estímulo interesante a la diversidad, pues subsidia el despliegue de redes, un costo importante para quien quiera radiodifundir contenidos. Según este modelo, TVN podría transformarse en una empresa estatal cuyo giro sea la provisión de la infraestructura de red necesaria para la emisión de señales televisivas digitales, con especial énfasis en la difusión de contenidos locales. Esta alternativa calza bien con la propuesta del proyecto que reforma la Ley 18.838, en el sentido que éste establece para la radiodifusión televisiva concesiones de servicios "intermedios" de telecomunicaciones, cuyo objeto "esencial" es, precisamente, el transporte de señales televisivas digitales. Así, en este modelo, TVN sólo sería titular, a lo largo de todo el territorio nacional, de concesiones de servicios "intermedios” para el transporte de señales televisivas digitales. Con esta infraestructura podría subsidiarse la emisión de contenidos por parte de los más variados titulares de concesiones de radiodifusión televisiva, sean locales, comunitarios u otros.

Si se inclinara en el sentido avanzado por estas líneas, la reforma legislativa que el Gobierno ha iniciado para preparar el marco regulatorio de la radiodifusión televisiva, ante la inminente llegada de la tecnología digital, daría sólo pasos hacia delante y ninguno hacia atrás.

\section{REFERENCIAS}

Colegio de Ingenieros de Chile A. G. (2008), Presentación ante la Comisión de Ciencia y Tecnología de la Cámara de Diputados, el 01/12/08. Disponible en http:// www.camara.cl/www/tv/CD/index.htm.

Corte Suprema (2000): Asociación Nacional de la Prensa Asociación Gremial y otro con Empresa de Transporte de Pasajeros Metro Sociedad Anónima, recurso de amparo económico, rol 248-2000, del 31/01/2000.

${ }^{24}$ Ver http://www.kordia.co.nz/about-kordia 
Sierra, Lucas (2001): “The Development of Law Goverining Television Broadcasting in Chile. 1958-2001”. Ph. D. Thesis, Cambridge University.

(2006): "Hacia la TV digital en Chile: Historia y transición”. En Estudios Públicos $\mathrm{N}^{\circ} 103$ (invierno), pp. 111-154. Disponible en http://www.cepchile.cl/ dms/lang_1/doc_3834.html.

- (2008): "Regulación de las Telecomunicaciones en Chile: Potestades Normativas, Tradición Divergente y Desafíos de la Convergencia”. En Subtel y Facea (eds.), Telecomunicaciones: Convergencia y Nuevos Desafíos. Santiago: Subtel y Facea, pp. 15-74.

Tribunal Constitucional (1995): Requerimiento formulado por diversos diputados para que el tribunal resuelva sobre la cuestión de constitucionalidad planteada durante la tramitación del proyecto sobre "Libertad de Expresión, Información y Ejercicio del Periodismo”, de acuerdo al Artículo 82, N² 2, de la Constitución Política de la República, Considerando 31을 sentencia Rol 226 de 30/10/1995. Disponible en http://www.tribunalconstitucional.cl/index.php/sentencias/download/pdf/391. 